\title{
A Model Of Information Technology Impacts: An Invariance Analysis By Executive Position
}

Robert W. Stone, (rstone@uidaho.edu) University of Idaho, Moscow David J. Good, (profdg4187@aol.com) Grand Valley State University

\begin{abstract}
The invariance, by executive position in the organization, of an information technology impacts model is examined. The theoretical model links computer training, end-user previous computer experience, information (provided by the system) quality, ease of system use, customer knowledge in the firm's industry, and the tasks performed using the system to individual and firm performance impacts through system use and satisfaction. The empirical examination uses data from a national mail survey. The respondents are business executives at four different organizational levels (i.e., owners, senior executives, marketing executives, and middleloperational executives). The quantitative technique used is invariance analysis based on structural equation modeling. The results indicate that the interrelationships among the theoretical constructs in the model are generally invariant across these different organizational positions. The one difference identified is the path from information quality to system use. Examining each executive group individually shows that this path is significant for marketing executives, but no other executive group. Thus, the identified difference appears to be produced by the importance of information quality on marketing executives' use of computer systems. Managerial implications, conclusions, and suggestions for future research are discussed based upon these results.
\end{abstract}

\section{Introduction}

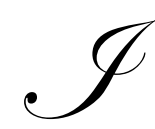

nformation technology (IT) is a widely discussed and implemented tool in organizations (Torkzadeh and Doll 1999). While it seems apparent that such technologies produce organizational value, assessment of its value remains a difficult issue. In spite of these difficulties (O'Brien 1997), the belief that technologies provide advantages is a driving force for many organizations to use information technology at significant levels (Stites 1999; Wipperfuth 1999) in a variety of functional areas (Good and Stone 1999). In addition, the cost of technology is enormous (Grover, Teng, and Fiedler 1998), often accounting for over two percent of revenues (Macmillan 1997). Despite its cost and extensive use, the degree to which using IT is rewarded in a competitive environment is not clear. It is popular to propose that the usage of technology provides high returns, yet evidence suggests this is not always true (Grover, Teng, and Fiedler 1998; Macmillan 1997). Technologies can, in fact, have uncertain, little, or no impact on profitability (O'Sullivan 1998). The question is then, what motives the extensive use and commitment of resources to IT? Given the difficulty in measuring the value of IT, the answer to this question appears founded in the managerial perceptions of IT and its performance impacts.

It has been proposed that a manager perceives a computer system and its application useful if it contributes to accomplishing the purposes of the end-user (Doll, Hendrickson, and Deng 1998). In other words, managers form expectations about the factors influencing and supporting system use as well as the impacts of system use on performance, based on how the system helps accomplish the purpose of the end-user. For business executives, this purpose depends upon the responsibilities of their position in the organization. As positions change by level of the organization or functional area, these responsibilities and interrelationships also change.

The purpose of this research is to explore differences or the lack of differences in the perceived interrelationships in a model linking information technology use to performance across managerial or executive positions. 
The model is theoretically sound, linking organizational, individual, information, industry, task, and information technology system characteristics to individual and firm performance. The premise for examining the invariance of this model across executive or managerial positions is based on differences in managerial performance, expectations, and perceptions due to differences in organizational position. The research question is do these interrelationships change based on differences in managerial or executive position in the organization?

\section{The Theoretical Model}

The theoretical model used is based upon the DeLone and McLean (1992) model and Goodhue and Thompson's (1995) task-technology-individual fit. The model describes how managers successfully utilize IT within their positional responsibilities to impact performance. Specifically, it is proposed that the traits of the organization, individual, and industry as well as system characteristics, the quality of the information provided and the tasks performed with the system influence the end-user's perceptions of system satisfaction and the degree of system use. System use and satisfaction, in turn, impact individual performance which ultimately impacts firm performance. Given that several of these constructs are very general, more specific constructs operationalize these general ones. The more specific operationalized constructs are computer training (i.e., organizational trait), end-user previous computer experience (i.e., individual trait), customer knowledge (i.e., industry traits), ease of system use (i.e., system characteristics), and information quality (i.e., quality of the information provided).

\section{The Hypotheses}

Because the purpose of the manuscript is to examine any differences in the interrelationships in the theoretical model, invariance analysis using structural equations was employed. This approach constrains subsets of parameters in the model to be equal across groups (i.e., executive position) and tests for meaningful differences in the constrained parameters. The subsets of constrained parameters and the order in which to constrain them depends on the purpose of the analysis (Doll, Hendrickson, and Deng 1998). Given the purpose here, the parameters are constrained in the following order. First, the paths from a construct to the indicants measuring it are constrained to be equal across organizational position, one construct at a time. The purpose of constraining these parameters is to identify fundamental differences in the measurement of the constructs across different organizational position so as not to be confused with differences in the model's interrelationships. Next, each path in the structural model (i.e., path between measured constructs) is constrained to be equal across executive position, one path at a time. The latter series of constraints focuses on the interrelationships in the theoretical model, the primary interest of the analysis. As such, these interrelationships are expressed by a series of hypotheses presented below.

Hypothesis One (H1):

Hypothesis Two (H2):

Hypothesis Three (H3):

Hypothesis Four (H4):

Hypothesis Five (H5):

Hypothesis Six (H6):

Hypothesis Seven (H7):

Hypothesis Eight (H8):

Hypothesis Nine (H9):
The impacts of computer training provided by the organization on system satisfaction vary by executive position in the organization.

The impacts of computer training provided by the organization on system use vary by executive position in the organization.

The impacts of the end-user's previous computer experience on system satisfaction vary by executive position in the organization.

The impacts of the end-user's previous computer experience on system use vary by executive position in the organization.

The impacts of information quality on system satisfaction vary by executive position in the organization.

The impacts of information quality on system use vary by executive position in the organization.

The impacts of the ease of system use on system satisfaction vary by executive position in the organization.

The impacts of the ease of system use system use vary by executive position in the organization.

The impacts of customer knowledge on system satisfaction vary by executive position in the organization. 
Hypothesis Ten (H10):

Hypothesis Eleven (H11):

Hypothesis Twelve (H12):

Hypothesis Thirteen (H13):

Hypothesis Fourteen (H14):

Hypothesis Fifteen (H15):
The impacts of customer knowledge on system use vary by executive position in the organization.

The impacts of tasks performed on system satisfaction vary by executive position in the organization.

The impacts of tasks performed on system use vary by executive position in the organization.

The impacts of system satisfaction on individual performance impacts vary by executive position in the organization.

The impacts of system use on individual performance impacts vary by executive position in the organization.

The impacts of individual performance impacts on firm performance impacts vary by executive position in the organization.

\section{The Sample}

A national mail survey with a target population of individuals who classified themselves as a manager/executive on a purchased mailing list was used to obtain the sample. The questionnaire was developed with items measuring the constructs in the model. A preliminary version of the questionnaire was pre-tested using 10 executives from several different managerial positions. These 10 individuals provided feedback regarding appropriateness, coverage, and readability of the questionnaire items. A total of 4000 questionnaires were mailed to managers/executives selected in a systematic random fashion from the mailing list. The usable returns numbered 562 for a response rate of approximately $14 \%$. Realizing that these individuals are executives who have limited time and who may interpret some of the items as dealing with key, confidential matters, the return rate is acceptable (Good and Stone 1995).

In order to test for the possible presence of non-response bias (discussed below) in the sample, a holdout group was formed. The questionnaires placed in the holdout group were selected by setting a cutoff date before mailing the questionnaire. Any questionnaires returned after this date were not considered part of the sample and were placed in the holdout group (Rainer and Harrison 1992). A total of 24 questionnaires were put in the holdout group, leaving 538 responses. Due to the type of analysis to be performed, 80 of the remaining responses were excluded from the sample due to missing values. This left 458 observations in the sample.

The demographic variables for the sample are displayed in Table 1. Within the sample, $74 \%$ of the respondents were male and $26 \%$ female. The firms employing the respondents had, on average, 452 employees with a range from 0 to 8000 employees and a median of 183. The average respondent age was 44 years with a range from 20 to 78 years and a median of 45 years. The respondents were also asked to report their highest level of education obtained. Nine percent reported high school, $13 \%$ reported a 2-year college, $51 \%$ a 4 -year college, $23 \%$ a masters degree, and $4 \%$ a doctorate. The years of previous computer experience averaged 12 years, ranging from a minimum of 0 years to a maximum of 40 years with a median of 11 years. There were two questions on the survey regarding current computer system use at work. The average percentage of time spent each day using the computer system was $44 \%$, ranging from $0 \%$ to $100 \%$ with a median of $40 \%$. In terms of the number of times each day the respondent uses the computer system at work, the average was 25 times and the range was from 0 to 100 times with a median of 10 times. In terms of the respondent's self-reported managerial or executive position in the organization, $19 \%$ were owners, $35 \%$ were senior executives, $21 \%$ were marketing executives, and $25 \%$ were middle/operational executives.

A couple of additional comments are needed regarding the sample and these demographics. Notice that some of the respondents included in the sample had zero years of previous computer experience while others expressed no daily computer use. Further, some respondents worked in organizations reporting zero employees. These individuals were not excluded from the sample so as to provide a full range of observations for analysis. 
Table 1

The Sample Demographics

Gender

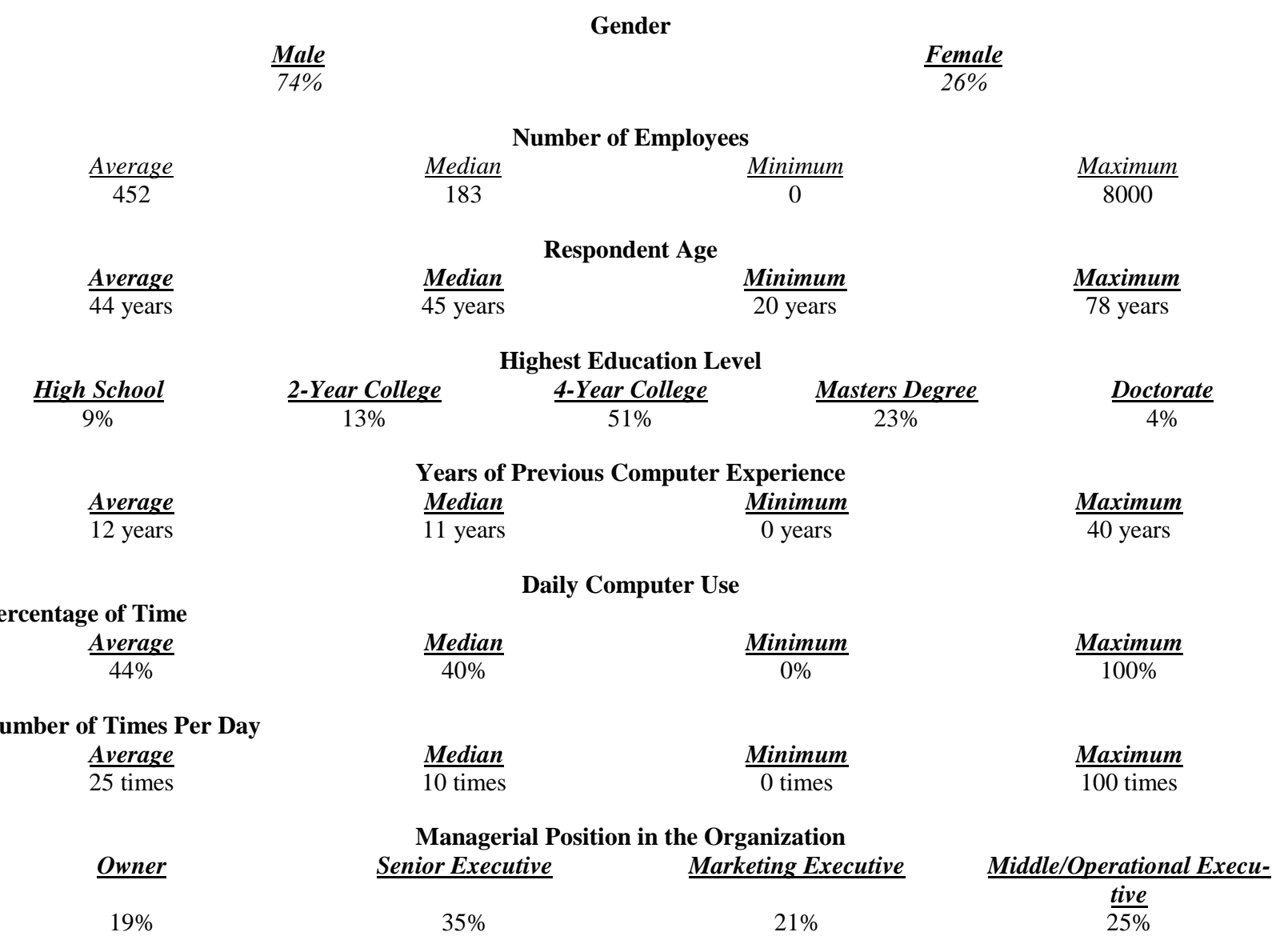

\section{The Measures}

The constructs defined in the theoretical model were operationalized by several measures formed from at least two questionnaire items. The questionnaire items are shown in Table 2. All the measures were either developed by the authors or previously published scales modified to the technology-oriented environment in which the instrument was utilized. Ease of system use and individual performance impacts were both adopted from work done by Good and Stone (1999). Information quality was adapted from the information usage (company sources) scale tested by Crosby and Stephens (1987) and the work of Doll and Torkzadeh (1988). System satisfaction was adapted from a job satisfaction scale used by Dubinsky et al. (1986). Customer knowledge was developed from Butaney and Wortzel's (1988) examination of market power of customer knowledge. Computer training was developed from a management support scale used by Henry and Stone (1995). The end-user previous computer experience measure was taken from the work of Good and Stone (2000). The firm performance impacts and tasks performed scales were created by the authors after a review of the literature and discussions with several business managers. System use was measured by the respondent's reported percentage of time at work they use the computer system. 
Table 2

The Indicants, Standardized Path Coefficient, Measures, and Their Psychometric Properties

\section{Measures and Their Indicants}

Computer Training

In my business firm.....

1. computer training is readily available.

2. the computer training provided is always excellent.

Information Quality

The computer systems at work provide.....

3. up-to-date information.

4. the information I need in time.

5. sufficient information.

6. information that is clear.

Ease of System Use

7. I find the computer easy to use.

8. I find it easy to get the computer to do what I want it to do.

Previous Computer Experience

9. I have used computers throughout my career.

10. I have used computer systems over a long period of time.

Customer Knowledge

11. Our customers possess a great deal of market information.

12. Our customers have knowledge about the market.

System Satisfaction

13. Overall, I am content with the computer systems at work.

14. Overall, I am pleased with how the computer systems at work facilitate my work.

15. Overall, the computer systems "fit well" what I need to at work.

16. Overall, I am satisfied with the computer systems at work.

Individual Performance Impacts

In my business/firm, computer systems.....

17. improve my work performance.

18. help make me more successful.

19. improve the quality of my work.

20. help me do a better job.

Firm Performance Impacts

The computer systems at work.....

21. are successful by improving organizational performance.

22. lead to a more successful organization.

23. lead to higher quality of work.

24. improve the marketplace success of the firm.

Tasks Performed

Indicate the degree to which computer technology in your business/firm has

been important in aiding performance in the following areas.....

25 . providing information for effective communication.

26. improving communication between my firm and customers.

27. Improving communication between members of my business/firm (e.g., sales force to manufacturing).

$\wedge$ Statistically significant at a $1 \%$ level.

\section{Path Coeffi- \\ cient \\ $0.87^{\wedge}$ \\ $0.88^{\wedge}$}

$0.81^{\wedge}$

$0.89^{\wedge}$

$0.77^{\wedge}$

$0.79^{\wedge}$

$0.90^{\wedge}$

$0.85^{\wedge}$

$0.83^{\wedge}$

$0.85^{\wedge}$

0.81

$0.66^{\wedge}$

$0.92^{\wedge}$

$0.90^{\wedge}$

$0.89^{\wedge}$

$0.95^{\wedge}$

0.88

$79 \%$

0.70

0.95

$84 \%$

0.94

$79 \%$

$0.93^{\wedge}$

$0.90^{\wedge}$

$0.93^{\wedge}$

$0.80^{\wedge}$

0.92

$74 \%$

$0.82^{\wedge}$

$0.90^{\wedge}$

$0.89^{\wedge}$

$0.82^{\wedge}$

0.85

$65 \%$

\section{Non-Response Bias}

$0.76^{\wedge}$

$0.82^{\wedge}$

$0.84^{\wedge}$

As in any study involving a survey, the possible presence of non-response bias is a concern. Comparing the holdout group to the sample for differences in demographic variables is one examination for the presence of nonresponse bias. A second is to perform a similar comparison for the summated measures used in the study. Both examinations were performed and are described below. 
The demographics variables not used directly in the invariance analysis were compared between the sample and the holdout group using t-tests (two-tailed using a 5\% significance level). The specific variables and t-values were: gender (-0.31); number of employees (0.39); respondent age (-0.73); the highest education level of the respondent (-1.30); years of previous computer experience (-0.14); and the number of times each day the system is used (0.38). No meaningful differences between the holdout group and the sample were identified across these demographics. The summated measures were also compared across the sample and the holdout group using t-tests. No meaningful differences were found between the holdout group and the sample. The t-values for each individual test of a summated measure were: computer training (-0.28); end-user computer experience (0.88); information quality (1.51); ease of system use (1.85); customer knowledge (-0.24); tasks performed (1.65); system satisfaction (0.89); system use (0.44); individual performance impacts (1.38); and firm performance impacts (2.06). Based on these results, it is concluded that non-response bias is not a serious problem for the study.

\section{The Psychometric Properties Of The Measures}

The evaluation of the measures' psychometric properties was based on the results from fitting the measured model to the complete data set using a structural equations approach. All the indicants were reflective of the constructs they measured. Each indicant was impacted by a disturbance term that was free to vary and with a path between the indicant and its disturbance term set equal to one. All the measured constructs were exogenous and scaled by setting their standard deviations equal to one. Each possible measure pair was allowed to pair-wise correlate. The estimation used CALIS (i.e., Covariance Analysis of Linear Structural Equations) in PC SAS version 6.12. The estimation method was maximum likelihood. The fit of the model to the data was good as described by several statistics. The goodness of fit index was 0.92 , while the comparative fit index was 0.97 . The normed fit index was 0.93 and the chi-square statistic was significant at 550.53 with 306 degrees of freedom. The normed chi-square statistic was 1.80 . These results and the large sample size imply a good fit between the model and the data (Hair, Anderson, Tatham, and Black 1987).

The psychometric properties of the measures were evaluated, as shown in Table 2, using these results. Since the standardized path coefficient to each indicant from its measure was at least as large as 0.66 , item reliability was satisfied (Nunnally 1978). Because the composite reliability coefficients ranged from 0.70 to 0.95 , composite reliability was satisfied (Rainer and Harrison 1993). All the average percentages of shared variance were 55\% or greater, demonstrating satisfactory levels of this trait (Rivard and Huff 1988). Due to these desirable values, it can be concluded that convergent validity was satisfied for each measure (Rainer and Harrison 1993; Igbaria and Greenhaus 1992).

Discriminant validity was also examined using these results. The examination compared the squared correlation between each pair of measures to their average percentage of shared variances. Discriminant validity is satisfied if, for each measure pair, the average percentages of shared variance are greater than the corresponding squared correlation (Fornell and Larcker 1981). These squared correlations ranged from 0.00 to 0.38 . Since the squared correlations were less than all the average percentage of shared variances already reported, discriminant validity was satisfied (Fornell and Larcker 1981). These results, coupled with convergent validity, imply that the measures satisfied construct validity (Rainer and Harrison 1993). Thus, the developed measures had desirable psychometric properties.

\section{The Method}

The empirical specification of the theoretical model shown in Figure 1 was developed as reflective in nature, with the path between a measure and its indicant pointing from the measure to the indicant. Each of these paths was free to vary, with the exception of one indicant for each measure that was used to scale the measure. Further, each indicant and endogenous measure was impacted by a disturbance term that was free to vary. The resulting model was evaluated for invariance following the multi-step approach described by Doll, Hendrickson, and Deng (1988) using AMOS (i.e., Analysis of Moment Structures) version 4.0. 
The first step in the analysis is to fit the model, unconstrained, to the entire data set. The idea is to make sure that the model fits the data before proceeding with additional analysis. With an unacceptable fit, there is no need to perform any additional steps. If the fit is acceptable, the next step is to independently fit the same model, unconstrained, in each of the four partitions or dimensions in the data set (i.e., fit the model individually to owners, senior, marketing, and middle/operational executives). Like in the previous step, the idea is to make sure the model fits the data before moving forward to the next step. Given acceptable fits, the next steps are a series of estimations in which selected parameters are constrained to be equal across all the data partitions (i.e., executive levels). As mentioned earlier, the selection and order of parameters to constrain is a matter of the focus for the research. For the study at hand, the order of analysis, after the unconstrained estimations discussed above, began with a set of estimations constraining the indicant paths to be equal across executive positions, one measure at a time. The next set of constrained estimations was to restrain one path in the structural model (i.e., hypothesized interrelationship) to be equal across executive position, one relationship at a time.

\section{The Unconstrained Estimations}

The fit of the model to the full data set was very good. The goodness of fit index was 0.91 while the comparative and normed fit indexes were 0.96 and 0.93 , respectively. The chi-square statistic was 709.323 with 321 degrees of freedom. Its value was significantly different from zero. However, the normed chi-square statistic was 2.21. Given this good fit, the next step of the analysis, fitting the model to the data from each executive position, was performed and produced marginally acceptable results. For the senior executives, the goodness of fit index was 0.83 and the comparative and normed fit indexes were 0.94 and 0.85 , respectively. The chi-square statistic was significantly different from zero at 486.21 with 321 degrees of freedom. In the other three data dimensions (i.e., owners, marketing executives, and middle/operational executives), the fits between the model and the data were at best marginal. The goodness of fit indexes ranged from 0.75 to 0.76 , the comparative fit indexes 0.89 to 0.93 , and the normed fit indexes from 0.75 to 0.83 . While these results were not outstanding, all the normed chi-square statistics for these estimations were less than 2. As a result, the fits were considered sufficient to continue with the analysis. All these fit results are shown in Table 3.

Table 3

The Fit of the Unconstrained Model in the Full Data Set and Each Executive Position

$\begin{array}{lcccccc}\text { Data Dimension } & \text { Chi-square } & \begin{array}{c}\text { Degrees of } \\ \text { Freedom }\end{array} & \begin{array}{c}\text { Normed } \\ \text { Chi-square }\end{array} & \begin{array}{c}\text { Goodness of } \\ \text { Fit Index }\end{array} & \begin{array}{c}\text { Compara- } \\ \text { tive Fit In- } \\ \text { dex }\end{array} & \begin{array}{c}\text { Normed Fit } \\ \text { Index }\end{array} \\ \text { Full Data Set } & 709.32^{\wedge} & 321 & 2.21 & 0.91 & 0.96 & 0.93 \\ \text { Owners } & 502.03^{\wedge} & 321 & 1.56 & 0.75 & 0.89 & 0.75 \\ \text { Senior Executives } & 486.21^{\wedge} & 321 & 1.51 & 0.83 & 0.94 & 0.85 \\ \text { Marketing Executives } & 521.12^{\wedge} & 321 & 1.62 & 0.75 & 0.93 & 0.83 \\ \text { Middle/ Operational Execu- } & 530.03^{\wedge} & 321 & 1.65 & 0.76 & 0.91 & 0.80 \\ \text { tives } & & & & & & \\ \text { ^ Significant at a 1\% level. } & & & & & & \end{array}$

\section{The Constrained Estimations}

The next step in the invariance analysis was performed by fitting the model to the complete data set with selected parameters constrained to be equal across the executive positions. The change in the chi-square statistic from the unconstrained fit to the constrained fit, both using the complete data set, was used to identify significant differences in the constrained parameters across executive positions. The first series of models constrained the indicant paths to be equal across executive positions, one measure at a time (i.e., the invariance of the measures). The final series of estimated models constrained selected paths in the structural model to be equal across executive groups, one path at a time (i.e., the invariance of the structural model paths). These paths are those stated in the hypotheses. 


\title{
The Invariance Of The Measures
}

The set of constrained estimations examining the invariance of the measures restrained the paths from a measure to its indicants to be equal across the executive positions, one measure at a time. A lack of invariance (i.e., meaningful differences in these indicant paths across executive positions) implies that these items and the resulting measure are perceived or interpreted differently across executive positions. On the other hand, invariance implies that the items and the resulting measures are perceived and interpreted similarly across executive position.

The results of this analysis indicated invariance of all the measures. The differences in the chi-square statistics from the unconstrained estimation to the appropriate constrained estimation found no differences based upon a 5\% significance level. These results, shown in Table 4, imply that the measures are perceived similarly across different organizational positions of the executives. Thus, any lack of invariance found in the next stage of the analysis (i.e., the structural model paths), does not have as its source differences in the measures of the constructs.

\section{Table 4}

The Invariance Analysis Results for the Constrained Indicant Paths to the Measures Across Executive Positions

\author{
Indicants Constrained to be Equal for: \\ Computer Training \\ Previous Computer Experience \\ Information Quality \\ Ease of System Use \\ Customer Knowledge \\ Tasks Performed \\ System Satisfaction \\ Individual Performance Impacts \\ Firm Performance Impacts \\ * Statistically significant at a 5\% level.
} $\begin{array}{ll}\begin{array}{l}\text { Difference in Chi- } \\ \text { square Statistics }\end{array} & \begin{array}{l}\text { Degrees of } \\ \text { Freedom }\end{array}\end{array}$

\section{The Invariance of the Structural Model Paths}

$\begin{array}{ccc}2.37 & 3 & 0.50 \\ 0.91 & 3 & 0.82 \\ 13.63 & 9 & 0.14 \\ 1.69 & 3 & 0.64 \\ 4.43 & 3 & 0.22 \\ 2.10 & 6 & 0.91 \\ 14.79 & 9 & 0.10 \\ 15.83 & 9 & 0.07 \\ 8.83 & 9 & 0.45\end{array}$

The individual paths in the model, as defined in the hypotheses, were also tested for invariance across the four groups of executives using the change in the chi-square statistic as described above. The results of these tests are reported in Table 5. Only the path from information quality to system use differed among the four groups of executives, using a 5\% significance level. The result implies that information quality has different impacts on system use across these groups of executives. Examining the estimations for this path in the unconstrained estimations within each executive position shows that it was significantly different from zero only for marketing executives. Thus, information quality significantly impacts a marketer's use of the system, but has no impact on system use by the other groups of executives. As a result, the impact of information quality on system use differed across the four executive groups, providing empirical support for hypothesis six. None of the other hypotheses were empirically supported by the analysis.

Also shown in Table 5 are the results from the final constrained estimation. In this estimation, all the paths in the structural model were restrained to be equal across all four executive positions. The result of this estimation found no meaningful differences across the executive positions for any of these paths. This result implies a general invariance of all the structural model paths (i.e., the hypotheses) as a group across the executive positions. 
Table 5

The Invariance Analysis Results for the Constrained Paths in the Structural Model Across Executive Positions

Constrained Individual Paths in the Structural Model

Computer Training to System Satisfaction

Computer Training to System Use

Previous Computer Experience to System Satisfaction

Previous Computer Experience to System Use

Information Quality to System Satisfaction

Information Quality to System Use

Ease of System Use to System Satisfaction

Ease of System Use to System Use

Customer Knowledge to System Satisfaction

Customer Knowledge to System Use

Tasks Performed to System Satisfaction

Tasks Performed to System Use

System Satisfaction to Individual Performance Impacts

System Use to Individual Performance Impacts

Individual Performance Impacts to Firm Performance Impacts

Constrained All Paths in the Structural Model

* Statistically significant at a 5\% level.

\section{Managerial Implications And Conclusions}

Within the context of the model examined and its measurement, the empirical results imply that the factors impacting computer system use and satisfaction and, ultimately individual and firm performance are generally invariant by executive level in the organization. In other words, the interrelationships depicted in the model appear generally not to change as the executive's organizational level changes. While these results do not support the hypotheses, the findings do provide significant insight for managerial actions.

From a management of technology perspective, the implication is that these variables may be universally managed across organizational levels. In general, if the context of use changes across organizational levels, the important variables and their interrelationships regarding the impacts from IT use will not. Generally, aspects regarding the management of IT may be standardized across executive positions without altering system satisfaction, use, or the performance impacts from using the system. What this suggests is that organizations do not have to make large resource investments to manage technology in seeking similar outcomes throughout executive and managerial levels. For instance, factors that impact the willingness of executives and owners of firms to use and receive satisfaction from the use of computers are apparently impacted by similar factors. As a result, it is possible in many cases for cross functional training (where different functional areas are included) to be a mainstay organizational strategy.

These results do not imply that individuals from obviously separate responsibility areas interpret all technological factors the same or, in fact, seek all the same outcomes. Instead, the findings simply confirm the similarity in how technology is seen by individuals from different organizational stations. Thus, these results must be interpreted with caution. The real issue is whether this research has truly identified universal factors or if these findings occur from the definition of the managerial levels examined or the measurement of the constructs used in the model. Future research is needed to clarify these issues.

\section{Suggestions For Future Research}

In order to more fully explore the invariance of this information technology impacts model, future research is needed in several directions. First, the results presented above need to be replicated to assure the findings are not functions of the sample or measures used. Beyond this verification, the invariance of these information technology 
impacts needs exploration across other dimensions of the firm and end-user. A study closely related to the one presented here would examine the question, do these impacts vary across functional area responsibilities of the enduser? An additional dimension to consider is the type of information technology application that is used. Do the impacts of information technology use differ by the specific application type (e.g., word processing, database applications) or the general classification of these systems (e.g., transaction processing system, decision support system).

\section{References}

1. Butaney, Gul and Lawrence H. Wortzel, "Distributor Power Versus Manufacturer Power: The Customer Role," Journal of Marketing, Vol. 52, (January), pp. 52-63, 1998.

2. Crosby, Lawrence A. and Nancy Stephens, "Effects of Relationship Marketing on Satisfaction, Retention, and Prices in the Life Insurance Industry," Journal of Marketing Research, Vol. 24, (November), pp. 404411, 1987.

3. DeLone, William H. and Ephraim R. McLean, "Information Systems Success: The Quest for the Dependent Variable," Information Systems Research, Vol. 3, (March), pp. 60-94, 1992.

4. Doll, William J. and Gholamreza Torkzadeh, "The Measurement of End-User Computing Satisfaction," MIS Quarterly, Vol. 12, No. 2, pp. 259-273, 1988.

5. Doll, William J., Anthony Hendrickson, and Xiaodong Deng, "Using Davis's Perceived Usefulness and Ease-of use Instruments for Decision Making: A Confirmatory and Multigroup Invariance Analysis," Decision Sciences Journal, Vol. 29, No. 4, pp. 839-869, 1998.

6. Dubinsky, Alan J., Roy D. Howell, Thomas N. Ingram, and Danny Bellenger, "Salesforce Socialization," Journal of Marketing, Vol. 50, (October), pp.192-207, 1986.

7. Fornell, Claes and David F. Larcker, "Evaluating Structural Equation Models with Unobservable Variables and Measurement Error," Journal of Marketing Research, Vol. XVIII, (February), pp. 39-50, 1981.

8. Good, David J. and Robert W. Stone, "The Impact of Computerization on Marketing Performance," Journal of Business \& Industrial Marketing, Vol. 15, No. 1, pp. 34-56, 2000.

9. Good, David J. and Robert W. Stone, "Working Smarter: The Impact of Technology on Marketer Motivation," Participation \& Empowerment: An International Journal, Vol. 7, No. (3), pp. 56-67, 1999.

10. Good, David J. and Robert W. Stone, "Computer Technology and the Marketing Organization: An Empirical Investigation," Journal of Business Research, Vol. 34, (November), pp. 197-209, 1995.

11. Goodhue, Dale L. and Ronald L. Thompson, "Task-Technology Fit and Individual Performance," MIS Quarterly, Vol. 19, (June), pp. 213-236, 1995.

12. Grover, Varun, James T.C. Teng, and Kirk D. Fiedler, "IS Investment Priorities in Contemporary Organizations," Communications of the ACM, Vol. 41, No. 2, pp. 40-48, 1998.

13. Hair, Joseph, Jr., Rolph E. Anderson, Ronald L. Tatham, and William C. Black, Multivariate Data Analysis: With Readings, MacMillan Publishing Company, New York, New York, 1992.

14. Henry, John W. and Robert W. Stone, "A Structural Equation Model of Job Performance Using a Computer-based Order Entry System," Behaviour \& Information Technology, Vol. 14, No. 3, pp. 163-173, 1995.

15. Igbaria, Magid and Jeffrey H. Greenhaus, "Determinants of MIS Employee's Turnover Intentions: A Structural Equation Model," Communications of the ACM, Vol. 35, (February), pp. 35-49, 1992.

16. Macmillan, Hugh, "Managing Information Systems: Three Key Principles for General Managers," Journal of General Management, Vol. 22, No. 3, pp. 12-23, 1997.

17. Nunnally, J., Psychometric Methods 2nd edition. McGraw-Hill, New York, New York, 1978.

18. O'Brien, Tia, "Redefining IT Value," Informationweek, Vol. April 7, pp. 71-76, 1997.

19. O’Sullivan, Orla, “Technology Spending's Uncertain Payback," Usbanker, Vol. 108, No. 9, pp. 32-44, 1998.

20. Rainer, R. Kelly, Jr. and Allison W. Harrison, "Toward Development of the End User Computing Construct in a University Setting," Decision Sciences Journal, Vol. 24, No. 6, pp. 1187-1202, 1993.

21. Rivard, S. and S. Huff, "Factors of Success for End-User Computing," Communications of the ACM, Vol. 31, No. 5, pp. 552-561, 1988.

22. Stites, Janet, “As Black Technology Entrepreneurs Organize, They Are Spreading the Word About the 
Benefits of Digital Freedom,” New York Times, Feb. 22, pp. C-4, 1999.

23. Torkzadeh, G. and W. J. Doll, "The Development of a Tool for Measuring the Perceived Impact of Information Technology on Work," Omega, Vol. 27, No. 3, pp. 327-339, 1999.

24. Wipperfuth, Heike, "Start-Up Foresees Exchange Pits in Cyberspace," The Investment Dealers' Digest, April 19, pp. 12, 1999. 
Notes 